\title{
SEQUÊNCIAS DIDÁTICAS INVESTIGATIVAS E ARGUMENTAÇ̃̃O NO ENSINO DE ECOLOGIA
}

\author{
Marcelo Tadeu Motokane* \\ Universidade de São Paulo (USP) \\ *Bacharel e licenciado em Ciências \\ Biológicas, mestre e doutor em \\ Ensino de Ciências pela Universidade \\ de São Paulo. Professor doutor \\ do Departamento de Biologia da \\ Faculdade de Filosofia, Ciências \\ e Letras de Ribeirão Preto, \\ Universidade de São Paulo (USP). \\ E-mail: mtmotokane@ffclrp.usp.br.
}

RESUMO: O presente artigo tem por finalidade apresentar os princípios que baseiam a produção das Sequências Didáticas Investigativas (SDI) do grupo de pesquisa LINCE (Linguagem e Ensino de Ciências). Tais sequências têm como foco o ensino de ecologia e se utilizam do processo de alfabetização científica e do ensino por investigação para promover a produção de argumentos em sala de aula e justificar a sua importância para a aprendizagem da ciência. As sequências apresentam problemas científicos que levam à construção de argumentos. As aplicações e as análises das sequências didáticas têm demonstrado que há espaço para o desenvolvimento de argumentos falados e escritos. Porém tem sido um desafio construir orientações para que o professor possa mediar as atividades com a finalidade de produzir argumentos válidos, baseados em conhecimentos científicos em suas justificativas.

Palavras-chave: Argumentação. Ensino de biologia. Alfabetização científica.

\section{SECUENCIAS DIDÁCTICAS INVESTIGATIVAS Y ARGUMENTACIÓN EN LA ENSEÑANZA DE LA ECOLOGÍA}

RESUMEN: Este artículo presenta los principios que basan la producción de las Secuencias Didácticas Investigativas (SDI) del grupo de investigación LINCE (Lenguaje y Enseñanza de las Ciencias). Tales secuencias tienen enfoque en la enseñanza de la ecología y utilizan el proceso de alfabetización científica y de la enseñanza por investigación para promover la producción de argumentos en aula y justificar su importancia para el aprendizaje de la ciencia. Las secuencias presentan problemas científicos que llevan a la construcción de argumentos. Las aplicaciones y los análisis de las secuencias didácticas han señalado que hay espacio para el desarrollo de argumentos hablados y escritos. Todavía, ha sido un desafío construir orientaciones para que el profesor pueda mediar las actividades con finalidad de producir argumentos válidos, basados en conocimientos científicos en sus justificativas.

Palabras clave: Argumentación. Enseñanza de la Biología. Alfabetización científica. 
INVESTIGATIVE DIDACTIC SEQUENCES AND ARGUMENTATION IN ECOLOGY TEACHING

ABSTRACT: This article presents LINCE (Language and Science Teaching) research group's principles to the investigative didactic sequences production. Such sequences focus on the teaching of ecology and use scientific literacy and inquiry-based teaching to promote arguments' production in classroom and justify science learning. The sequences presented scientific problems that led to arguments' construction. Applications and analysis of didactic sequences has shown that there is room for spoken and written arguments' development. However, it has been a challenge to build guidelines for the teacher to mediate the activities in order to produce valid arguments based on scientific knowledge in their justifications.

Keywords: Argumentation. Biology teaching. Scientific literacy. 


\section{INTRODUC̣ÃO}

A biologia ensinada nas escolas carregou por muitos anos o estigma de ter uma quantidade excessiva de terminologias e descrições exaustivas de processos e estruturas. Sem dúvida alguma, o componente descritivo da biologia é necessário para a compreensão de vários fenômenos e faz parte da linguagem biológica, porém esses excessos fizeram as aulas de biologia serem conhecidas pela memorização de nomes de filos, ciclos e processos e produziram uma percepção de uma ciência estanque, de verdades prontas e acabadas.

É na tentativa da superação de algumas dessas dificuldades que este artigo busca discutir o uso da alfabetização científica como base teórica para a produção de Sequências Didáticas Investigativas (SDI) que tenham o desenvolvimento da argumentação como foco.

Apresento, neste artigo, cinco ideias que guiam a construção de sequências didáticas no grupo de pesquisa LINCE ${ }^{1}$ (Linguagem e Ensino de Ciências), que atua na área de ensino de biologia.

A primeira ideia apresenta o que entendemos por sequência didática e como essa compreensão organiza e estrutura de modo mais amplo as atividades que são propostas. Essa ideia garante que a construção de uma sequência possa ter uma estrutura mínima de fácil identificação pelo professor.

Os temas de destaque de nossas sequências estão relacionados com a ecologia. Entendida como a ciência que estuda as relações dos seres vivos entre si e destes com o meio, a ecologia deixou de compreender tais relações de modo mecanicista e passou a ter um papel importante nas decisões de políticas de conservação em todo o mundo. Conforme afirmam Keller e Golley (2000), a ecologia não pode escapar de fazer juízos de valor sobre a natureza, o que dá a ela um caráter ético, o qual precisa ser compreendido para que as decisões possam ser tomadas de maneira crítica e coerente. Dessa forma, a segunda ideia para a construção de sequências didáticas do grupo LINCE é que todas tenham como foco a ecologia, entendida na sua complexidade e considerando suas interfaces com outras áreas de conhecimento.

A preocupação do nosso grupo de pesquisa em produzir sequências nessa área se dá em função da grande frequência com que os temas ambientais surgem na sala de aula. Em geral, os conteúdos de ecologia nas aulas de biologia, e mesmo nos livros didáticos, seguem tratamentos semelhantes, pois estão baseados na descrição de definições e processos. Raramente há situações de trabalho de campo, apesar de as pesquisas apontarem que seu uso pode estimular a aprendizagem e contribuir para uma melhor compreensão dos processos ecológicos (SENICIATO; CAVASSAN, 2004; FERNANDES, 2007; LOPES; PONTUSCHKA, 2009; GRANDI; MOTOKANE, 2012).

É comum que os alunos decorem os nomes das interações ecológicas, os ciclos biogeoquímicos, as classificações de níveis tróficos ou mesmo que tenham contato com as discussões sobre problemas ambientais locais ou globais. 
No último caso, os alunos participam de uma série de discussões sobre temas ambientais, porém dificilmente conseguem relacionar as suas opiniões com os conceitos científicos aprendidos em sala de aula. Também são raras as situações nas quais os alunos podem compreender como a ecologia produz conhecimento e quais são seus objetos e suas metodologias.

Assim, concordamos com Sasseron e Carvalho (2011) quando descrevem quais seriam os eixos estruturantes da alfabetização científica na educação básica. Tais eixos, quando utilizados no ensino de ecologia, são importantes para garantir um ensino mais contextualizado e menos "mecânico", quais sejam: 1) compreensão básica de termos, conhecimentos e conceitos científicos fundamentais; 2) compreensão da natureza das ciências e dos fatores éticos e políticos que circundam sua prática; e 3) entendimento das relações existentes entre ciência, tecnologia, sociedade e meio ambiente. Portanto, temos como terceira ideia a estruturar nosso trabalho de construção de Sequências Didáticas Investigativas (SDIs) a importância de alinhá-las com as propostas de uma alfabetização científica que promova a educação libertadora, de modo a auxiliar a formação de cidadão crítico, capaz de compreender a ecologia e utilizar seus conhecimentos na sua vida.

Ao tratarmos do ensino de ecologia, os temas ambientais passam a ser muito frequentes nos currículos de biologia a partir dos anos de 1980 e têm cada vez mais tomado espaço na vida das pessoas. Porém assuntos como esses trazem para a sala de aula uma diversidade de opiniões e ideias. Mediar tais debates para que promovam a aprendizagem é um desafio para todos os professores. Como sair da simples emissão de opiniões baseadas apenas no senso comum para opiniões que estejam fundamentadas no conhecimento científico?

Assim, a quarta ideia que temos nas nossas sequências didáticas é a de que o desenvolvimento de argumentos fundamentados em conceitos científicos pode ser indicador da aprendizagem da ecologia. Portanto, as sequências procuram desenvolver situações nas quais os alunos expressem seus argumentos, sejam eles na forma escrita ou falada.

Para justificar a proposição das sequências didáticas, apresento como quinta ideia qual é a concepção de sequência didática investigativa que temos em nosso grupo de pesquisa, uma vez que essa é uma abordagem de grande importância para garantir a participação efetiva dos alunos durante as aulas.

Portanto, o objetivo do presente trabalho é apresentar quais são as premissas e as características das sequências didáticas investigativas de ecologia produzidas pelo grupo de pesquisa LINCE as quais promovem a argumentação.

\section{O QUE SÃO SEQUÊNCIAS DIDÁTICAS INVESTIGATIVAS}

A ideia de construção de sequências didáticas investigativas necessita de um esclarecimento, uma vez que sua compreensão é muito variada. Não é objetivo deste item discutir todas as concepções de sequência didática que estão presentes 
na literatura, mas, sim, apresentar a concepção mais geral que guia a produção de sequências didáticas pelo nosso grupo de pesquisa.

De um modo mais geral, sequências didáticas podem ser consideradas como um conjunto de atividades ordenadas, estruturadas e articuladas para a realização de certos objetivos educacionais, que têm um princípio e um fim conhecidos tanto pelos professores como pelos alunos (ZABALA, 1998). As sequências didáticas também podem ser vistas como "certo número de aulas planejadas e analisadas previamente com a finalidade de observar situações de aprendizagem, envolvendo os conceitos previstos na pesquisa didática" (PAIS, 2002, p. 102). Assim, as sequências didáticas são utilizadas para o ensino, uma vez que são produzidas por nós para serem aplicadas nas salas de aula pelo professor de ciências e biologia.

As sequências didáticas também podem ser consideradas e são pensadas para ser uma ferramenta para a coleta de dados nas investigações em educação científica. Historicamente, nos cenários nacional e internacional, as sequências didáticas têm sido utilizadas como instrumentos de planejamento do ensino e também como objetos de pesquisa, criando condições favoráveis para os alunos se apropriarem de ferramentas culturais próprias da comunidade científica (ALMOULOUD; COUTINHO, 2008), permitindo a análise desse processo e estimulando o diálogo entre a pesquisa no ensino de ciências e a sala de aula.

Nas sequências do grupo LINCE, as atividades são programadas para que possam ser realizadas em uma ou duas aulas, e seus produtos são claramente definidos. Quanto a estes, há uma atenção especial às produções de textos escritos que estimulem os alunos a emitirem opiniões e expressarem conceitos científicos. Procura-se, nas aulas, promover momentos que sistematizem informações e encaminhamentos de atividades para as aulas seguintes, bem como retomadas importantes para o desenvolvimento de atividades futuras.

No trecho a seguir, a sequência didática investigativa trata de um problema no qual os alunos devem decidir qual é o componente do fator biótico que determina a quantidade de duas espécies vegetais em dois locais diferentes. No fim dessa atividade, há um conjunto de informações sistematizadas na forma de um texto explicativo e uma frase que o aluno deve preencher com palavras adequadas à hipótese que foi levantada. Essa frase é um dos fechamentos que será retomado em outro momento da sequência didática investigativa.

Assim, esses besouros acabam destruindo o embrião da planta, que se encontra dentro da semente, impedindo que uma nova planta cresça e se desenvolva; em outras palavras, esses insetos predam a semente porque eles matam a planta contida na semente, assim como um leão preda uma zebra ou uma aranha preda um gafanhoto; tanto o besouro que come a semente, como o leão e a aranha nesses casos, podem ser chamados portanto de predadores. Desse modo, Jacó, partindo de seus conhecimentos sobre predação, elaborou a seguinte hipótese para tentar explicar a diferença entre a vegetação do Local A e a vegetação do Local B (mapa 1).

Hipótese 1: A predação é a causa da diferença entre as vegetações.

Qual foi a relação que Jacó provavelmente criou? 
Quanto (maior ou menor?) a taxa de predação, (maior ou menor?) o $\mathrm{n}^{\mathrm{o}}$ plantas da espécie predada, porque

(FREIRE, 2014, p. 93)

Nas pesquisa acadêmicas realizadas pelo grupo LINCE, essa organização auxilia na escolha de momentos da aula que poderão compor os futuros dados para as análises. A identificação dessa estrutura auxilia o professor a organizar sua aula, a propor tarefas e a produzir transformações nas sequências, promovendo a autoria na construção da aula. A construção dessa autoria se faz necessária para que o professor possa ter mais segurança no uso da sequência e na adoção de uma abordagem investigativa. Antes da aplicação das SDIs, é possível que o professor faça modificações, como a inclusão de novos temas, atividades ou produções que sejam adequadas à realidade da sala de aula.

Essa construção de uma identificação do professor com a SDI, apontando tanto complementações como limitações, é uma etapa importante, pois é a partir dela que podemos fazer modificações na estrutura geral para novas aplicações em sala de aula.

\title{
A ABORDAGEM INVESTIGATIVA
}

Quando tratamos de uma abordagem investigativa para as sequências didáticas, concordamos com Carvalho (2013. p. 9):

\begin{abstract}
Nesse contexto teórico é que propomos as sequências de ensino investigativas (SEIS), isto é, sequência de atividades (aulas) abrangendo um tópico do programa escolar em que cada atividade é planejada, do ponto de vista do material e das interações didáticas, visando proporcionar aos alunos: condições de trazer seus conhecimentos prévios para iniciar os novos, terem ideias próprias e poder discuti-las com seus colegas e com o professor passando do conhecimento espontâneo ao científico e adquirindo condições de entenderem conhecimentos já estruturados por gerações anteriores.
\end{abstract}

As SDIs criadas pelo grupo LINCE seguem a estrutura proposta por Carvalho (2013), segundo a qual criamos um contexto para a apresentação de um problema científico (experimental ou teórico). O problema instiga, estimula e provoca os alunos a partirem para a resolução. Ao longo do desenvolvimento da SDI, são propostas atividades de sistematização por meio do material de apoio. Muitas vezes, durante as atividades, o professor retoma assuntos importantes e traz novas perguntas para serem resolvidas. O trecho transcrito no trabalho de Valle (2014, p. 115) ilustra essa situação em sala de aula.

Profa .: Só para a gente lembrar... já que o texto que eu vou apresentar fala sobre cracas... a pergunta que não quer calar né?... o que são cracas?

Aluna 5: São seres vivos.

Prof ${ }^{a}$ : São seres vivos. 


\begin{abstract}
Aluno 1: Marítimos!
\end{abstract}
Prof ${ }^{a}$ : : Marítimos.

Aluno 1: Que vivem fixos nas... rochas.

Aluno 3: Ah! ... Como é que é?...é...

Aluna 9: Hermafroditas!

Prof ${ }^{a}$.: Hermafroditas... hummm! Você caprichou hein? O que é hermafrodita? Você sabe o que quer dizer hermafrodita?

Aluna 9: Que tem os dois sexos, os dois órgãos reprodutores... não nem sempre órgãos reprodutores... eles têm... os dois... gametas.

Nesse momento da aula, a professora abre espaço para os alunos expressarem suas ideias, concordando com as terminologias empregadas por eles e estimulando o surgimento de novas questões, como é o caso do hermafroditismo em cracas.

Já no trecho seguinte, a professora estimula o raciocínio lógico e dá espaço para dúvidas e conversas entre os alunos para explicar um fenômeno. Essa prática, além de estabelecer uma participação efetiva do aluno, pode auxiliá-lo a compreender que, na produção do conhecimento científico, a livre circulação de ideias é fundamental para o avanço da ciência.

Prof ${ }^{a}$.: E eles fizeram a experiência e estão mostrando através do gráfico que o resultado foi diferente... então olha só... onde a população de Chthamalus consegue ter um desenvolvimento melhor e aparecer um maior número de indivíduos?... Quando?... Em que situação? Alunos: Na primeira.

Prof ${ }^{a}$.: Na primeira quando eles estão sozinhos. Todo mundo conseguiu entender o experimento?

Aluna 7: Aham!

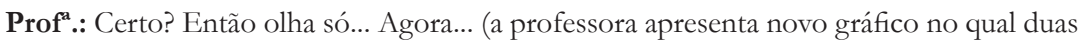
espécies de cracas diferentes estão no mesmo local, mostrando uma diminuição da espécie Chthamalus sp.)

Aluno 1: Porque que diminui?

Prof ${ }^{a} .:$ Ah!... Boa pergunta! Por que é tão pequena... tão inferior essa taxa?

Aluno 3: Porque vai ter disputa ... e provavelmente a Tetraclita ganha!

Em muitas das sequências didáticas do grupo LINCE, há relação muito direta com a realidade vivida pelos alunos, mesmo que essa realidade tenha sido construída por meio de uma atividade de campo em local distante daquele onde os alunos residem. Esse foi o caso da SDI proposta por Valle (2014), na qual alunos do interior do Estado de São Paulo discutiram aspectos da dinâmica de comunidades de seres vivos marinhos de um costão rochoso no litoral de São Sebastião (SP).

\title{
A ECOLOGIA DE TODOS OS DIAS
}

A ecologia apresentada nas escolas de educação básica, em geral, figura como um dos temas de mais frequência na sala de aula. Mas de qual ecologia estamos falando? 
Pesquisas como a de Manzochi (1994), quando a autora analisou os currículos de ciências e biologia de Campinas (SP), já mostravam que a ecologia tinha diferentes abordagens dentro de sala de aula. As principais abordagens eram as de ecologia natural, na qual o foco de estudo eram os ecossistemas e seu funcionamento; ecologia humana/social, entendida como uma ciência que estuda a evolução cultural frente às pressões ambientais, passando pela sociobiologia, a etnobiologia e por estudos sobre demografia e epidemiologia; conservacionismo, que é visto pela autora como uma ecologia mais prática, um conjunto de ideias e estratégias voltadas para a luta em favor da conservação e da preservação da natureza; e, por fim, a abordagem chamada de ecologismo, que é entendida como um projeto político de transformação social, calcado em princípios ecológicos e no ideal de uma sociedade comunitária e não opressiva.

Em trabalhos mais recentes, como os de Contin e Motokane (2012) - no qual entrevistaram alunos de ensino médio sobre a concepção que tinham sobre ecologia -, constatou-se que boa parte das definições dos alunos estava próxima das abordagens do conservacionismo e do ecologismo, tendo havido poucas em relação à ecologia humana/social e nenhuma a respeito da ecologia natural. As frequências das falas que expressam as duas primeiras abordagens são muito altas quando comparadas às das outras. $\mathrm{O}$ conservacionismo aparece com uma frequência de 56,3\%, e o ecologismo, de $68 \%$. Os trechos a seguir, retirados de Contin (2012, p. 45), ilustram as informações.

Eu acho que pra tudo. Porque se a pessoa toma banho, se ela sabe sobre ecologia, ela não ia gastar tanta água... É... Na hora de reciclar as coisas, se ela sabe bem ela vai reciclar ao invés de jogar tudo num lixo só. Essas coisas... (entrevistado 1 - abordagem conservacionismo)

O entrevistado 1 expressa a necessidade do consumo consciente e que as atitudes das pessoas estão baseadas em um conhecimento que a ecologia irá proporcionar. Porém o entrevistado não menciona quais seriam esses saberes importantes para a mudança dessas atitudes.

Ainda em Contin (2012), o entrevistado 9 mostra sua preocupação com a preservação e afirma que a mudança de atitude deve ocorrer em nome de um bem coletivo (meio ambiente). Apesar de expressar a ideia de que a transformação da sociedade está baseada no conhecimento que a ecologia promove, ao mesmo tempo, ele entende que ecologia pode ser o próprio ambiente.

Porque, como meu pai diz: com tanta informação, com tanta gente fazendo, é... sobre os perigos que pode acontecer daqui pra frente, (acho que) não tem a consciência pra... pra sei, lá. Pra... Pra preservar, pra cuida melhor, porque isso tudo aqui é nosso e, isso tudo, se a gente não cuida, não fizer nada, vai acabar! Acaba com tudo, com toda a diversidade... Todo, é, como pode dizer, ecologia, que a gente tem aqui... (entrevistado 9 - abordagem ecologismo). (CONTIN, 2012, p. 75) 
Essas foram constatações importantes, uma vez que boa parte do trabalho desenvolvido nas escolas se refere a temas que estão nas abordagens de ecologia natural. A maior parte dos livros didáticos traz definições que pertencem a essa abordagem. Alguns capítulos são dedicados a temas relacionados ao conservacionismo e ao ecologismo e pouco se fala sobre ecologia humana/social.

Freire (2014) faz uma análise de 8 livros didáticos de biologia que foram aprovados no Programa Nacional do Livro Didático para o Ensino Médio (PNLEM 2007/2009) e constata que o conceito de "interações ecológicas" é abordado em nível de organismo em todas as coleções. Os livros enfatizam o efeito que uma interação ecológica tem para o indivíduo, dando pouca ou nenhuma importância para o efeito dessa interação em outros níveis de organização, como, por exemplo, para a população, a comunidade ou o ecossistema.

O autor também constata que as questões e as atividades propostas aos alunos envolvendo o conceito de interações não são questões problematizadoras. Portanto, não estimulam práticas que aproximem os alunos do fazer científico, tais como: levantar e testar hipóteses, estabelecer relações de causa e efeito, controlar variáveis, expressar raciocínio lógico e proporcional, interpretar dados provenientes de diferentes fontes, elaborar modelos explicativos, entre outros.

Portanto, mesmo com a abordagem da ecologia natural sendo predominante na maior parte dos livros didáticos, os alunos não estão próximos da prática investigativa que caracteriza as SDIs que propomos. Ao pensarmos nas SDIs sobre ecologia, partimos do princípio de que o estudo de conceitos ecológicos é importante, uma vez que tais conceitos embasam os argumentos para a tomada de decisão sobre problemas ambientais.

Todas as nossas sequências didáticas possuem foco em um ou mais conceitos de ecologia, que são apresentados de forma clara e explícita durante o decorrer das aulas. Esses conceitos estão claros para o professor tanto no que se refere ao seu arcabouço conceitual quanto em relação à sua inserção nos currículos de ciências e biologia. Não só os professores, mas também os alunos têm consciência de quais são os conceitos ecológicos que irão aprender ao longo do desenvolvimento da sequência didática. Em vários momentos, são realizadas retomadas, para que os conceitos sejam relembrados e utilizados em diferentes situações.

No Quadro 1 apresentamos os temas das sequências didáticas produzidas e os principais conceitos que são envolvidos em cada uma delas. 
Quadro 1: Relação de temas das SDI e os conceitos trabalhados.

\begin{tabular}{|c|c|}
\hline TEMA & CONCEITOS \\
\hline $\begin{array}{l}\text { MATA ATLÂNTICA } \\
\text { Freire (2014) }\end{array}$ & $\begin{array}{l}\text { Predação } \\
\text { Competição } \\
\text { Modelo de Jansen-Connel } \\
\text { Ecossistema } \\
\text { Biodiversidade }\end{array}$ \\
\hline $\begin{array}{c}\text { RESTINGA } \\
\text { Yamada (2013) }\end{array}$ & $\begin{array}{l}\text { Fatores abióticos } \\
\text { Adaptação } \\
\text { Características da Restinga } \\
\text { Ecossistema } \\
\text { Biodiversidade }\end{array}$ \\
\hline $\begin{array}{c}\text { COSTÃO ROCHOSO } \\
\text { Valle (2014) }\end{array}$ & $\begin{array}{l}\text { Fatores bióticos } \\
\text { Fatores abióticos } \\
\text { Característica de Costão Rochoso } \\
\text { Zonação } \\
\text { Ecossistema } \\
\text { Princípio de Gause (ou exclusão competitiva) } \\
\text { Biodiversidade }\end{array}$ \\
\hline $\begin{array}{l}\text { POLINIZAC̣ÃO } \\
\text { Cover (2012) }\end{array}$ & $\begin{array}{l}\text { Interações entre seres vivos } \\
\text { Polinização } \\
\text { Reprodução } \\
\text { Fecundação }\end{array}$ \\
\hline $\begin{array}{c}\text { REFLORESTAMENTO } \\
\text { Grandi (2011) }\end{array}$ & $\begin{array}{l}\text { Sucessão Ecológica } \\
\text { Comunidade } \\
\text { População } \\
\text { Cadeia alimentar } \\
\text { Teia alimentar } \\
\text { Recuperação de áreas degradas } \\
\text { Biodiversidade }\end{array}$ \\
\hline
\end{tabular}

Fonte: Elaboração pelo autor deste artigo.

Todas as SDIs procuram trazer um conjunto de conceitos ecológicos que são facilmente reconhecidos pelo professor como conhecimento escolar. Essa característica tem por finalidade aumentar a aproximação do professor com as atividades propostas. Se ele identifica conteúdos conceituais próprios da ecologia, é possível que a SDI faça sentido em algum momento do currículo que o professor organiza. Essa também é uma característica importante, pois, em outros momentos de nossas pesquisas, muitos professores expressaram a queixa de que as ações de pesquisa no interior da sala de aula não deixavam produtos claros para serem utilizados posteriormente.

\section{AS SEQUÊNCIAS DIDÁTICAS E A ALFABETIZAC̣̃̃o CIENTÍFICA}

A alfabetização científica caracteriza-se como um processo no qual os alunos podem compreender como os cientistas veem, falam e explicam os 
fenômenos naturais. Não se trata de formar "cientistas" na escola, mas, sim, de promover acesso a uma forma de produção de conhecimento. Nessa perspectiva, o acesso a essa cultura promove a inserção do indivíduo na lógica e na prática científicas e lhe proporciona a chance de entender o mundo sob o ponto de vista da ciência.

Em Sasseron e Carvalho (2011), as autoras apresentam os eixos estruturantes da alfabetização científica que são utilizados pelo grupo LINCE para produzir as sequências didáticas que podem promover a argumentação em sala de aula. $\mathrm{O}$ eixo compreensão básica de termos, conhecimentos e conceitos científicos fundamentais já foi parcialmente contemplado quando abordamos a questão da importância do ensino de conceitos ecológicos fundamentais e da sua explicitação, tanto para alunos como professores, nas sequências didáticas. Todas as SDIs apresentam momentos nos quais alunos e professores reconhecem a importância de terminologias e conceitos fundamentais para a organização da aula, como mostra o trecho a seguir, retirado das atividades para os alunos (YAMADA, 2013, p. 78).

Essas plantas recebem menor influência da ação do mar (salinidade) e dos ventos. O terreno é mais estável, e as condições de fixação das raízes das plantas melhoram. Dependendo da época do ano, ocorre acúmulo de água da chuva. E ao contrário da região onde predominam as herbáceas, existe sobre o solo da vegetação arbustiva uma camada fina de serrapilheira (restos vegetais como folhas, caules, frutos, flores) que entra em decomposição e fornece nutrientes para as plantas.

No trecho destacado, palavras como "serrapilheira", "fixação", "herbáceas", "decomposição" compõem um vocabulário que será utilizado durante a SDI no sentido de melhorar a comunicação entre os falantes e descrever melhor os processos que são discutidos. Não há necessidade de memorização das terminologias, e a qualquer momento os alunos podem consultar as definições ou perguntar ao professor qual é o melhor uso dos termos.

Outras características das SDIs também convergem para esse eixo. Um dos momentos que os professores têm dificuldades para desenvolver são os fechamentos de aula ou sistematizações. Essa etapa deve ser encaminhada de modo a evitar que a aplicação da SDI se torne uma mera reprodução de textos ou falas do professor. Para que os alunos possam ter momentos nos quais sejam realizados fechamentos de discussões ou mesmo sistematizações de conteúdos trabalhados, as sequências didáticas oferecem materiais de apoio que possibilitam a construção de justificativas pertencentes ao campo do conhecimento ecológico. Esses materiais podem ser textos escritos provenientes de mídias impressas e eletrônicas ou ainda imagens de satélites, mapas, fotos, gráficos, tabelas, entre outros.

Segundo trabalho de Contin e Motokane (2012), mais de 60\% dos jovens entrevistados utilizavam a internet como meio de informação sobre assuntos referentes à ecologia. Esse dado foi importante para as sequências, pois em algumas delas há sugestões de sites ou vídeos que podem ser acessados na rede mundial. Assim, sequências didáticas procuram desenvolver uma linguagem apropriada e 
compartilhada com os alunos. Nesse sentido, há orientações explícitas para os professores sobre a importância dessa mediação. Essa orientação é consequência de trabalhos do grupo, como o de Yamada e Motokane (2013, p. 39), sobre a mediação dos professores na elaboração de textos escritos pelos alunos, no qual os autores afirmam:

[...] Mas, por meio desta pesquisa foi possível observar a importância do papel do professor e do material utilizado em sala de aula. $\mathrm{O}$ aluno em seu processo de construção de conhecimento apresenta fases em que se apropria de discursos alheios. Sendo assim, no processo de alfabetização científica, é importante que o discurso do professor e o material utilizado em sala de aula estejam conectados, uma vez que os alunos reproduzem tanto o que é considerado cientificamente aceito, mas também termos e ideias equivocadas. Uma vez internalizados os discursos equivocados, mais difícil será a desconstrução desse conhecimento formado.

Nessa mediação, é importante que o professor contemple aspectos da ciência e da linguagem e esteja atento para a fala, a leitura e a escrita dos alunos; ele é um mediador de todas essas produções presentes na sequência. Segundo Sutton (2003), o professor de ciências deve ser entendido também como professor de linguagem, uma vez que ensina os alunos a compreenderem e reproduzirem o modo como os cientistas falam e escrevem sobre o mundo que os cerca.

Para discutirmos o segundo eixo, compreensão da natureza das ciências e dos fatores éticos e políticos que circundam sua prática, é preciso apresentar a ideia de problema que está presente nas atividades das sequências didáticas. Construímos nossas atividades sob a perspectiva do ensino por investigação, priorizando a resolução de problemas científicos com o objetivo de promover situações argumentativas e explicativas.

O ensino por investigação caracteriza-se pela proposição de um problema cuja resolução exija o diálogo e permita a liberdade intelectual dos estudantes, levando-os ao desenvolvimento de interações e práticas discursivas importantes do fazer científico, como: descrições, explicações, argumentações, generalizações, entre outras (CARVALHO, 2013). O ponto de partida das sequências é uma situação problematizadora ou um problema autêntico. Segundo Jiménez-Aleixandre e Puig (2010), um problema autêntico é aquele que não tem uma resposta óbvia, implicando uma situação contextualizada que o aluno reconhece como interessante, e o processo de solução é tão importante quanto a própria resolução do problema.

Todas as sequências didáticas do grupo LINCE possuem um problema claro e explícito baseado em problemas da ciência. O contexto criado para apresentação do problema tem por finalidade criar um "cenário" no qual os alunos devem interagir para que possam explicar ou descrever os fenômenos observados. Nesse cenário eles reconhecem dados importantes e conceitos que podem levá-los às respostas possíveis.

Freire (2014) propõe um problema no qual os alunos devem decidir qual o motivo da diferença na composição de espécies vegetais de dois locais de mata atlântica. Esse problema traz um contexto para a discussão do modelo Jansen- 
-Connell. Os trabalhos desses dois ecólogos tiveram uma importância muito grande para as discussões sobre biodiversidade e para a ecologia de modo mais amplo. Assim, o problema procura produzir uma situação semelhante àquela dos trabalhos que deram origem ao modelo de Janzen-Connell em 1970, porém, fazendo uso de exemplos mais próximos da realidade brasileira.

Já a tese de Valle (2014) produziu uma SDI na qual eram descritos estudos feitos em costões rochosos com crustáceos de duas espécies diferentes. O princípio da exclusão competitiva, ou princípio de Gause, era o principal conceito a ser ensinado. Segundo ele, duas espécies que disputam os mesmos recursos tendem a competir até que uma delas possa ser eliminada do local onde há o recurso. Esse é outro conceito importante retirado de trabalhos clássicos da ecologia marinha. Os alunos são colocados diante da situação experimental por meio de desenhos, fotos e esquemas e devem em seguir escolher uma hipótese e justificá-la.

O trabalho de Cover (2012) apresenta uma SDI proveniente de pesquisas recentes em uma área de reserva ecológica na Bahia. O problema proposto trata da polinização por insetos e tem um conjunto de dados expressos na forma de gráficos e tabelas, que devem ser consultados para se chegar à solução. No trecho seguinte, o problema apresentado para os alunos é uma adaptação do trabalho original dos ecólogos.

Muitas vezes, a resolução de um problema leva a outro problema, como foi o caso da sequência didática analisada por Freire (2014). As atividades elaboradas para essa pesquisa tinham como foco um problema maior, que, para ser respondido, passou por etapas de reconhecimento de dados, levantamento de hipóteses e conclusões que levavam a um novo problema com as mesmas etapas. $\mathrm{O}$ conjunto das várias conclusões dos problemas parciais levou à resposta do problema maior. Quanto a isso, outra exigência da sequência didática é que todas as conclusões possibilitem utilizar o conjunto de dados apresentados e interpretados, de forma que indiquem a compreensão do problema, e de conceitos para explicar ou descrever fenômenos.

O terceiro eixo da alfabetização científica, entendimento das relações existentes entre ciência, tecnologia, sociedade e meio ambiente, é contemplado por meio de várias características das sequências. Entendemos que a participação ativa do aluno nas aulas permite que as ideias circulem livremente e que sejam passíveis de contestações ou concordâncias. Nessa condição os problemas são discutidos, e formas diferentes de resolvê-los são propostas, assim, novos problemas vão surgindo.

Ao mesmo tempo que a SDI contempla a necessidade de resolver um problema, também contempla uma das características da produção do conhecimento científico, que é a sobreposição de objetos e metodologias de estudo presentes nos diferentes saberes. Nesse sentido, ao resolverem um problema, os alunos trazem dúvidas e questionamentos provenientes de diferentes áreas do conhecimento ou mesmo da relação dos assuntos estudados com questões relativas à tecnologia ou ao meio ambiente. 
As análises de redações que Motta (2014, p. 45) realiza mostram algumas das relações que os alunos estabelecem com sua realidade mais próxima quando discutem sobre o reflorestamento de uma área da cidade.

O canavial porque é melhor para a humanidade e também com a floresta não se gera dinheiro. E também as pessoas não pensam no futuro. E só pensar em dinheiro. E sem a plantação de cana não teremos o açúcar e o álcool. Então a floresta não tem tanta importância. (Redação I.38)

Eu escolho a floresta porque na cidade já há muitos canaviais por causa da usina e aqui não há florestas e muita plantação de cana. E com uma floresta por perto o ar mudaria para melhor. Eu, na minha opinião, o canavial prejudica nas queimadas ele. A abertura do dossel do canavial e 100 por cento de luz solar e não há condição de um animal crescer em um canavial, e muito quente. (Redação I.29)

Temas como a biodiversidade também têm sido propícios para a construção de sequências didáticas em sala de aula ou espaços não formais de ensino. As pesquisas do grupo apontam o potencial pedagógico que esse tema tem de integrar várias áreas do conhecimento, ensinar conceitos ecológicos e estabelecer relações com questões de valores éticos, morais, econômicos e estéticos (GRANDI et al., 2014; MOTOKANE; KAWASAKI ; OLIVEIRA, 2010).

\section{A ARGUMENTAC̣ÃO NAS SEQUÊNCIAS DIDÁTICAS INVESTIGATIVAS}

O desenvolvimento de habilidades argumentativas em aulas de ciências é uma necessidade premente apontada e defendida por vários pesquisadores (KUHN, 1993; DRIVER; NEWTON; OSBORNE, 2000; OSBORNE; ERDURAN; SIMON, 2004). Baseados na ideia de que há pouco espaço para a argumentação em sala de aula, os pesquisadores do grupo LINCE buscaram, na produção das sequências, o desenvolvimento dessas habilidades.

Consideramos que a produção de argumentos em sala de aula oferece uma forma de entendermos como é a apropriação do conhecimento científico e ajuda-nos a identificar quais são as dificuldades que os alunos apresentam na produção do texto escrito. Ao exercitar suas habilidades argumentativas, os alunos aprendem como é a estrutura de um argumento e podem utilizá-la para a construção de opiniões mais bem-fundamentadas. Isso ocorre de diversas formas nas SDIs; em alguns casos, são apresentados aos alunos modelos de textos que devem ser seguidos, explicitando-se a estrutura de um argumento. Em outros casos, os alunos são estimulados a apresentarem suas opiniões baseadas em conhecimentos científicos, mas sem uma estrutura específica para o argumento.

O desenvolvimento de habilidades argumentativas também promove a exteriorização da aprendizagem de um conteúdo ensinado quando os argumentos têm a chance de ser produzidos com base em elementos científicos aprendidos em aula. Ao apresentarem seus argumentos, os alunos podem expressar como 
utilizam um determinado conceito científico para justificar uma opinião. Dessa forma, temos um indicador claro da aprendizagem do aluno.

A argumentação, segundo Jiménez-Aleixandre e Diaz (2003), consiste em avaliar enunciados teóricos por meio de dados empíricos ou provenientes de outras fontes, relacionando dados e conclusões. Os argumentos considerados válidos seriam aqueles que utilizam o conhecimento científico como base para estabelecer as relações entre os dados e as conclusões.

A estrutura do argumento que o grupo LINCE utiliza é a de Toulmin (2006). Para o autor, a estrutura do argumento é comparada a um organismo que consiste em unidades anatômicas e fisiológicas. A unidade mais bruta seria a "anatômica", composta por seus "órgãos", e apresentaria os elementos componentes do argumento. Já a unidade mais fina, o nível "fisiológico" de funcionamento do organismo, seria aquela na qual residem as sentenças individuais ou a lógica de cada frase.

Desse modo, o argumento, segundo o padrão de Toulmin (2006), conteria os seguintes elementos:

- Dado ou informações factuais que se invocam para validar a afirmação;

- Conclusão, que é a tese estabelecida;

- Garantias, que são proposições que autorizam as relações entre os dados e a conclusão.

- Apoios, que são os conhecimentos formais que asseguram as garantias.

- Qualificadores modais, que são elementos que dão suporte às conclusões, tornando-as mais fortes.

- Refutadores, que consistem nas circunstâncias ou nas condições para as quais as garantias não se aplicam.

O padrão de Toulmin (2006) é uma ferramenta importante para o grupo de pesquisa LINCE, pois, além de definir os elementos que compõem um argumento, o modelo estabelece com clareza as relações entre eles. As relações entre dados e conclusões por meio de garantias de caráter hipotético destacam as limitações das teorias científicas, bem como sua sustentação em outras teorias. O uso de qualificadores ou de refutações indica uma compreensão clara do papel dos modelos na ciência e a capacidade de ponderar diante de diferentes teorias a partir das evidências apresentadas por cada uma delas.

Motta (2014), analisando redações de alunos do $6^{\circ}$ ano de uma escola pública do interior paulista, evidencia argumentos que podem ser utilizados como indicadores da aprendizagem do conceito. Segundo o autor, é possível notar que as garantias apresentadas pelos alunos são provenientes de procedimentos e conceitos científicos que validam a conclusão. O refutador é outro elemento que indica a aprendizagem, uma vez que ele é construído somente no momento em que temos ciência das limitações do argumento que produzimos.

Os trechos a seguir fazem parte de extratos de textos que foram analisados e classificados por Motta (2014), desenvolvidos em uma atividade na qual os alunos deveriam escolher o que fazer com uma área pública de grandes dimensões: 
fazer uma área de recomposição vegetal ou um canavial. Para isso, os alunos contavam com uma série de informações obtidas por meio de um trabalho de campo realizado em uma área de canavial e em uma área de recomposição vegetal no interior paulista.

\section{Redação C.2}

Dado que (dado): O número de plantas é de mais ou menos 13 na floresta.

As árvores são mais altas na floresta.

A floresta é um local fresco.

No canavial a serrapilheira variou de $1 \mathrm{~cm}$ até $14 \mathrm{~cm}$,

Assim (conclusão): A floresta tem maior diversidade.

Já que (garantias): Árvores mais altas possibilitam mais vida.

Locais frescos são locais de maior diversidade.

No canavial as pessoas jogam folhas enquanto na floresta a serrapilheira é produzida naturalmente.

A menos que (refutador): Alguém tenha se confundido na coleta de dados.

(MOTTA, 2014, p. 59)

No próximo exemplo analisado por Motta (2014), é possível perceber que a estrutura e o conteúdo do argumento são mais complexos, ou seja, há mais elementos do padrão de Toulmin (2006). Além disso, os conteúdos utilizados em cada um dos elementos são pertinentes ao campo da ciência, em especial aos conhecimentos ecológicos.

Dado que (dado): A floresta muda no mínimo $2^{\circ} \mathrm{C}$ no clima, deixando mais fresco.

A floresta tem grande quantidade de serrapilheira.

A floresta limpa o ar.

$\mathrm{Na}$ floresta existem mais de 14 espécies de árvores.

O dossel da floresta é mais fechado, já o canavial tem 100\% de luz solar.

As árvores do canavial crescem até $2 \mathrm{~m}$ de altura e tem $5 \mathrm{~cm}$ de serrapilheira

Nossa cidade está acostumada com o canavial.

Assim (conclusão): Eu escolho a floresta.

Já que (garantias): A serrapilheira nutri o solo e serve de abrigo para os insetos.

A floresta tem biodiversidade.

Por conta de (apoio): Sabermos que biodiversidade significa vários tipos de animais, árvores, fungos, bactérias, dentre outros.

Podermos diferenciar as espécies pelas formas das folhas e nervuras.

A menos que (refutador): Você esteja pensando nos empregos que o canavial gera.

(MOTTA, 2014, p. 70)

A construção de SDIs que pudessem promover a construção de argumentos que seguissem o padrão de Toulmin foi o foco do trabalho do grupo por muito tempo. Esse formato da SDI prioriza a abertura de atividades com contextos que aproximam os alunos dos problemas que serão abordados; estes são problemas científicos que podem ou não ter um contexto sociocientífico. Como já exemplificado anteriormente, muitos dos problemas nascem de um trabalho científico que traz os fundamentos da ecologia. Assim, os problemas possuem um 
caráter científico muito claro, de modo que, ao longo da execução da SDI, pode haver um desenvolvimento que leve para questões sociocientíficas.

Para estruturar e guiar o desenvolvimento dos problemas científicos, as sequências utilizam um dos modelos propostos por Erduran (2006): "Predição-Observação-Explicação" ou "Teorias Concorrentes”. Esses modelos promovem a avaliação de diferentes explicações para um mesmo fenômeno e estimulam a argumentação com base em evidências. Além disso, esses modelos podem ser interessantes para o planejamento das SDIs, uma vez que elas também trazem momentos de problematização e sistematização. Organizar a SDI tendo como base esses modelos pode ser mais profícuo para o planejamento, uma vez que promove mais oportunidades para que os alunos possam expressar suas ideias sobre o problema e confrontá-las com as dos colegas.

No modelo de Predição-Observação-Explicação, a primeira etapa é o levantamento de hipóteses - explicações temporárias para o problema / fenômeno em questão. Em seguida, as hipóteses explicativas são testadas e avaliadas com base em dados (observações), e, finalmente, os alunos devem construir, por meio da argumentação, um modelo explicativo final capaz de resolver o problema.

No modelo de Teorias Concorrentes, além do problema, são fornecidos aos alunos um conjunto de dados e dois ou mais modelos explicativos para o fenômeno. Nesse tipo de atividade, os alunos devem simplesmente decidir qual modelo consideram o mais correto, justificando suas escolhas por meio da argumentação.

$\mathrm{Na}$ SDI produzida por Cover (2012), a estrutura segue as proposições do Modelo Predição-Observação-Explicação. A SDI inicia-se com a elaboração de um problema a ser resolvido pelo aluno. O problema engloba diferentes áreas da biologia entrelaçadas com a ecologia. É proposta uma atividade de observação de fotos com um conjunto de perguntas sobre características morfológicas de abelhas, as quais determinam diferentes tipos de fecundação durante a polinização, e, consequentemente, diferentes taxas de frutificação. A predição se dá pela contextualização da pesquisa e pela descrição morfológica da árvore de barbatimão; o aluno levanta uma hipótese para explicar a observação que o próprio cientista fez em campo.

Ainda em Freire (2014), na fase de observação, o aluno tem em mãos uma sequência de gráficos que corroboram algumas das hipóteses possivelmente levantadas nas etapas anteriores, mas é instigado por mais uma questão levantada pelo cientista. A etapa da explicação acontece quando o aluno é desafiado a dar explicações a respeito da situação fornecida. Nessa fase, o aluno conta com um texto de apoio, que fornece bases teóricas para a resolução da questão, e com todos os outros dados fornecidos por figuras e gráficos ao longo das outras atividades. Finalizando a sequência didática, o professor retoma as primeiras considerações feitas pelos alunos, verificando (avaliando) se houve mudanças de concepções ou, então, o quanto as explicações tornaram-se mais completas e baseadas em conteúdo científico. Além disso, o professor verifica se existem dúvidas e direciona as discussões delineando o conteúdo proposto. 
A SDI proposta por Freire (2014) apresenta dois ciclos de Predição-Observação-Explicação. O início da SDI é a apresentação do problema. A primeira predição ocorre quando, apoiando-se em dados teóricos sobre o ciclo de vida de besouros predadores de sementes, os alunos fazem inferência sobre a relação entre taxas de predação de sementes e abundância de plantas. Segue-se, então, à primeira observação, na qual os alunos usam dados empíricos (observacionais) sobre as taxas de predação das espécies vegetais nas duas florestas para avaliar a validade da predição feita na etapa anterior. Na sequência ocorre a segunda predição, na qual, apoiando-se em dados teóricos sobre competição entre plantas, os alunos inferem a relação entre abundância de uma espécie vegetal mais competitiva e abundância de uma menos competitiva. A segunda observação ocorre quando os alunos usam os dados empíricos (experimentais) sobre a competição entre as espécies vegetais para avaliar a validade da predição feita na etapa anterior. Terminando a SDI, a última etapa é caracterizada pela construção e pela defesa de uma explicação final para o fenômeno abordado, com base em todos os dados fornecidos. A ideia é perceber a insuficiência de cada hipótese para resolver o problema quando considerada isoladamente e construir um modelo explicativo envolvendo ambas as predições.

A SDI proposta por Azevdo (2013) utilizou o modelo de teorias concorrentes, a qual propunha atividades nas quais os alunos deveriam escolher entre um modelo explicativo darwinista e outro teleológico (que em geral reflete as concepções espontâneas), apresentados como duas formas diferentes de explicar o problema, e elaborar argumentos para justificar tanto a escolha de um modelo quanto a não escolha do outro. Nessa SDI, foram apresentadas aos alunos três situações sobre adaptações de seres vivos, e os alunos deveriam escolher qual texto apresentava uma explicação para o surgimento da adaptação. A análise desses argumentos gerou dados importantes para compreendermos como as explicações teleológicas foram formadas com base em informações presentes no material de apoio e na fala do professor. Um dado interessante dessa pesquisa foi que $18 \%$ das redações dos alunos continham argumentos completos sob o ponto de vista do padrão de Toulmin (2006), com dados, conclusões e garantias. Com relação às escolhas de modelos explicativos, das 66 redações analisadas, somente uma defendeu um modelo explicativo mais próximo da evolução por seleção natural.

Todas as sequências didáticas pressupõem a autonomia dos educadores para adequar as atividades às especificidades dos contextos nos quais atuam; sabendo que cada escola e cada turma tem suas particularidades, é essencial que estes profissionais, que são conhecedores dessas particularidades, façam alterações na sequência para que ela atenda às demandas de cada turma. Dessa forma, o professor pode fazer alterações como: trazer outros exemplos, incluindo alguns da sua realidade local; explicar gráficos e tabelas; mudar a ordem das perguntas e das atividades; inserir outras perguntas; acrescentar elementos que tenham relação com assuntos tratados em aulas anteriores ou a serem tratados em momentos posteriores do curso; utilizar as ideias e as dúvidas dos alunos para fomentar a 
discussão; pedir para que os alunos façam as atividades sozinhos ou em pequenos grupos; substituir vídeos por textos e slides por esquemas na lousa, entre outros.

\section{AS CARACTERÍSTICAS DAS SEQUÊNCIAS DIDÁTICAS INVESTIGATIVAS}

Por fim, apresentamos uma síntese das características principais das sequências didáticas do grupo LINCE, elencando-as de forma resumida a seguir:

1. A participação ativa do aluno surge como um elemento importante, uma vez que os alunos discutem suas ideias e as dos colegas, propondo problemas e suas resoluções e compartilhando suas impressões de forma livre.

2. As atividades são programadas para que possam ter começo, meio e fim em cada aula, possibilitando fechamentos e sistematizações aula a aula.

3. Os conceitos científicos são foco da aprendizagem e estão declarados de modo explícito para alunos e professores. Esses conceitos são parte do conteúdo programático das escolas, a fim de criar uma identidade da SDI com o trabalho que o professor já realiza. Esse é um item de fundamental importância para estimular o professor a utilizar a SDI em suas aulas.

4. Nas atividades, há produção de textos escritos, que devem ser corrigidos e partilhados em sala de aula. As devolutivas das produções são mediadas pelos professores e fundamentais para a aquisição de elementos da linguagem científica.

5. Muitas atividades também envolvem a leitura de textos, que podem complementar as informações das aulas, sistematizar conhecimentos, promover novas perguntas ou trazer os conteúdos para uma realidade mais próxima da vida do aluno. Algumas atividades de leitura podem, ainda, fundamentar debates e estimular o posicionamento perante uma questão científica ou sociocientífica.

6. Há um problema claro e explícito baseado em problemas da ciência. $\mathrm{O}$ ponto de partida das atividades é uma situação problematizadora ou um problema autêntico. Além disso, todos os problemas são passíveis de resolução pelos alunos.

7. Há um conjunto de dados claros para embasar as conclusões. Esses dados podem ser provenientes de atividades experimentais ou teóricas. Tais conclusões devem trazer os dados interpretados.

8. Os alunos recorrem a materiais de apoio de diferentes tipos para construir as justificativas no campo do conhecimento científico. Como as atividades de leitura e escrita são de grande importância para o desenvolvimento das SDIs, é necessário que as informações sejam apresentadas em diferentes suportes, tais como: vídeos, páginas da rede mundial, buscadores de informação, textos impressos, imagens impressas produzidas por diferentes equipamentos, entre outros.

9. As atividades permitem que a linguagem seja modulada pelo professor, para que os alunos utilizem terminologias e conceitos adequados e para que essa utilização seja compartilhada entre os alunos. Ele é o mediador de todas essas produções. 
10. Todas as SDIs têm a possibilidade de inclusões e adaptações necessárias para o bom andamento das aulas, respeitando a realidade de cada escola e sala de aula.

\section{CONSIDERAC̣ÕES FINAIS}

O grupo LINCE tem estudado as sequências didáticas de ecologia, e as pesquisas têm evidenciado que o espaço para a argumentação acontece em sala de aula. Nossos resultados revelam que temas científicos geram argumentos e que tais argumentos melhoram sua qualidade em função da mediação do professor. Quando analisamos os elementos dos argumentos, evidenciamos que algumas práticas são promotoras de produtos argumentativos escritos e falados que têm seus apoios e garantias baseados em conhecimentos científicos. Apesar de a construção dos argumentos acontecer, tem sido uma questão emergente a de como auxiliar os professores a mediarem a construção de argumentos válidos, ou seja, com garantias, dados e apoios baseados em conhecimento científico.

Outra questão que nos parece importante é que, para a construção das sequências didáticas investigativas, há um estudo prévio dos conhecimentos científicos, o qual deve ser feito pelo professor ou pesquisador que fará a elaboração das atividades. Essa é uma etapa fundamental, pois o planejamento da construção do argumento só será possível se o professor tiver clareza da complexidade dos conhecimentos científicos a serem ensinados.

Nas próximas etapas de pesquisa, o grupo LINCE iniciará uma fase de construção de instrumentos de avaliação das sequências considerando aspectos como análises produzidas pelo software ALCESTE. Motta (2014) já apresenta algumas tentativas desse uso para a categorização dos argumentos válidos. Essa é uma perspectiva interessante, pois possibilitará uma análise mais completa do argumento.

Outro desafio para o grupo é a elaboração de grades de análise quantitativas que levem em consideração as habilidades cognitivas exigidas dos alunos. Isso se faz necessário pois os argumentos produzidos nas diversas pesquisas do grupo mostram que há um conjunto distinto de habilidades que levam à produção dos argumentos. No desenvolvimento das SDIs, várias dessas habilidades são requeridas e ensinadas, e, por meio da avaliação da produção de argumentos, poderíamos chegar a um mapeamento de como ocorrem o ensino e a aprendizagem de tais habilidades ao longo da SDI.

A construção de uma ferramenta de análise que possa avaliar o grau de interface da ecologia com outros conhecimentos seria um ponto importante para avaliarmos se os argumentos produzidos fazem as conexões com a realidade dos alunos e com outras áreas do conhecimento, uma vez que defendemos a ideia de que os conhecimentos ecológicos têm grande interação com a sociedade e a tecnologia. Assim, poderíamos ter uma noção mais completa de como e em que momentos a SDI possibilitaria a interdisciplinaridade. 
Por fim, a avaliação do aprofundamento conceitual exigido na construção de cada argumento pode nos dar uma informação mais precisa das diferenças que detectamos quando analisamos os argumentos. Com essa avaliação, poderemos orientar melhor os professores para que estes possam auxiliar os alunos a construírem argumentos utilizando o conhecimento científico.

\section{NOTA}

${ }^{1}$ O grupo LINCE tem parceiros de pesquisa em áreas como educação, ecologia e botânica. Tais parceiros são de grande importância para as trocas de experiências sobre o formato das sequências didáticas, como é o caso do GEPEB (Grupo de Pesquisa em Ensino de Biologia, coordenado pela Profa. Dra. Silvia Trivelato), ou para questões relacionadas ao conhecimento científico próprio das áreas da biologia, como é o CEEFLORUSP (Centro de Estudo e Extensão da Floresta da USP, coordenado pela Profa. Dra. Elenice Mouro Varanda). Além disso, as Diretorias de Ensino de São João da Boa Vista, Catanduva, Sertãozinho, Registro e Barretos, assim como as Secretarias Municipais de Educação de Ribeirão Preto e Dumont, têm realizado cursos de formação continuada de professores de ciências naturais que aplicam nossas sequências didáticas em sala de aula.

\section{REFERÊNCIAS}

ALMOULOUD, S. A.; COUTINHO, C. D. Q. E. S. Engenharia Didática: características e seus usos em trabalhos apresentados no GT-19/ANPEd. REVEMAT: Revista Eletrônica de Educação Matemática, Florianópolis, SC, v. 3, p. 62-77, 2008.

AZEVEDO, R. C. Análise dos argumentos sobre adaptação. 2013. 89 f. Dissertação (Mestrado em Ensino de Ciências, modalidade biologia) - Faculdade de Educação, Instituto de Física, Instituto de Química e Instituto de Biociências, Universidade de São Paulo, São Paulo, 2013.

CARVALHO, A. M. P. O ensino de Ciências e a proposição de sequências de ensino investigativas. In: __ (org.) Ensino de Ciências por investigação: Condições para implementação em sala de aula. Editora: Cengage Learning, 2013.

CONTIN, C. A imagem da Ecologia em alunos do ensino médio de Ribeirão Preto. 2012. 84 f. Monografia (Bacharelado em Ciências Biológicas, área de concentração Ensino de Biologia) - Faculdade de Filosofia Ciências e Letras de Ribeirão Preto, USP, Ribeirão Preto, 2012.

CONTIN, C.; MOTOKANE, M.T. A imagem da ecologia em alunos do ensino médio do município de Ribeirão Preto. Revista do EDICC (Encontro de Divulgação de Ciência e Cultura), UNICAMP, Campinas, v. 1, p. 58-66, 2012.

COVER, C. D. Práticas pedagógicas promotoras da argumentação no ensino de ecologia. 2012. 65 f. Monografia (Bacharelado em Ciências Biológicas) área de concentração Ensino de Biologia) - Faculdade de Filosofia Ciências e Letras de Ribeirão Preto, USP, Ribeirão Preto, 2012.

DRIVER, R.; NEWTON, P.; OSBORNE, J. Establishing the norms of scientific argumentation in classrooms. Science Education, Madison, v. 20, p. 1059-1073, 2000.

ERDURAN, S. Promoting ideas, evidence and argument in initial science teacher training. School Science Review, Hatfield, v. 87, p. 45-50, 2006.

FERNANDES, J. A. B. Você vê essa adaptação? A aula de campo em ciências entre o retórico e o empírico. 2007. 338 f. Tese (Doutorado em Educação) - Faculdade de Educação, Universidade de São Paulo, São Paulo, 2007. 
FREIRE, C. C. Argumentação e explicação no ensino de ecologia. 2014. 97 f. Dissertação (Mestrado em Ensino de Ciências, modalidade biologia) - Faculdade de Educação, Instituto de Física, Instituto de Química e Instituto de Biociências, Universidade de São Paulo, São Paulo, 2014.

GRANDI, L. A. O argumento no trabalbo de campo: abordando a sucessão ecológica na floresta da USP, campus de Ribeirão Preto. 2011. 264 f. Dissertação (Mestrado em Ensino de Ciências, modalidade biologia) - Faculdade de Educação, Instituto de Física, Instituto de Química e Instituto de Biociências, Universidade de São Paulo, São Paulo, 2011.

GRANDI, L. A.; MOTOKANE, M. T. O potencial pedagógico do trabalho de campo em ambientes naturais: o ensino de biologia sob a perspectiva da enculturação científica. Educere: Revista da Educação, Umuarama, v. 12, n. 1, p. 59-72, 2012.

GRANDI, L. A.; CASTRO, R. G.; MOTOKANE, M. T.; KATO, D. S. Concepções de monitores e alunos sobre o conceito de biodiversidade em uma atividade e trabalho de campo. Cadernos CIMEAC, Ribeirão Preto, v. 4, n. 1, p. 5-21, 2014.

JIMÉNEZ-ALEIXANDRE, M. P; DIAZ DE BUSTAMANTE, J. Discurso de aula y argumentación en la classe de Ciencias: Cuestiones Teóricas y Metodológicas. Enseñanza de las Ciencias, Barcelona, v. 21, n. 3, p. 259-370, 2003.

JIMÉNEZ-ALEIXANDRE, M. P.; PUIG, B. Argumentación y evaluación de explicaciones causales en ciencias: el caso de la inteligência. Alambique, Barcelona, Año 15, n. 63, p. 11-18, 2010.

KELLER, D. R.; GOLLEY, F. B. Ecology as a Science of Synthesis. In: Ecology: from Science to synthesis. Georgia: University of Georgia Press, 2000. p. 1-19.

KUHN, D. Science as argument: implications for teaching and learning scientific thinking. Science Education, Madison, v. 77, n. 3, p. 319-337, 1993.

LOPES, C. S.; PONTUSCHKA, N. N. Estudo do meio: teoria e prática. Geografia, Londrina, v. 18, n. 2, p. 173-191, 2009.

MANZOCHI, L. H. Participação do ensino de ecologia em educação ambiental voltada para a formação da cidadania: a situação das escolas de $2^{\circ}$ grau no município de Campinas. 1994. 581 f. Dissertação (Mestrado em Ecologia) - Instituto de Biologia, Universidade de Campinas, Campinas, 1994.

MOTTA, A. E. M. O uso de dados empíricos na construção de argumentos escritos em aulas de Ciências Naturais. 2014. 85 f. Monografia (Bacharelado em Ciências Biológicas, área de concentração Ensino de Biologia) - Faculdade de Filosofia, Ciências e Letras de Ribeirão Preto/USP, Ribeirão Preto. 2014.

MOTOKANE, M. T.; KAWASAKI, C. S.; OLIVEIRA, L. B. Por que biodiversidade pode ser um tema para o ensino de ciências? In: MARANDINO, M. Olhares sobre os diferentes contextos da biodiversidade: pesquisa, divulgação e educação. São Paulo: GEENF/FEUSP/INCTTOX, 2010, p. 30-60.

OSBORNE, J.; ERDURAN, S.; SIMON, S. Enhancing the quality of argumentation in school science. Journal of Research in Science Teaching, Champaign, v. 41, p. 994-1020, 2004.

PAIS, L. C. Didática da Matemática: uma análise da influência francesa. Belo Horizonte: Autêntica, 2002.

SASSERON, L. H.; CARVALHO, A. M. P. Alfabetização Cientifica: uma revisão bibliográfica. Investigações em Ensino de Ciências, Porto Alegre, v. 16, n. 1, p. 59-77, 2011.

SENICIATO, T.; CAVASSAN, O. Aulas de campo em ambientes naturais e aprendizagem em ciências: um estudo com alunos do ensino fundamental. Ciência \& Educação, Bauru, v. 10, n. 1, p. 133-147, 2004.

SUTTON, C. Los profesores de ciencias como profesores de linguaje. Enseñanza de las Ciencias, Barcelona, v. 21 (1), p. 21-25, 2003.

TOULMIN, S. E. Os usos do argumento. 2. ed. São Paulo: Martins Fontes, 2006.

VALLE, M. G. Movimentos e práticas epistêmicos e suas relações com a construção de argumentos em aulas de ciências. 2014. 165 f. Tese (Doutorado em Educação, área de concentração Ensino de Ciências e Matemática) - Faculdade de Educação, Universidade de São Paulo, São Paulo, 2014.

YAMADA, M.; MOTOKANE, M. T. Alfabetização Científica: apropriações discursivas no desenvolvimento da escrita de alunos em aula de Ecologia. Revista Práxis, Volta Redonda, v. 5, n. 10, p. 29-40, 2013. 
YAMADA, M. A mediação docente na produção de textos escritos em aulas de ecologia. Dissertação (Mestrado em Ensino de Ciências - modalidade biologia) - Faculdade de Educação, Instituto de Física, Instituto de Química e Instituto de Biociências, Universidade de São Paulo, São Paulo, 136 p, 2013. ZABALA, A. A prática educativa. Porto Alegre: Artmed, 1998. 